\title{
Maternal pre-pregnancy underweight and the risk of small-for-gestational-age in Asian-American ethnic groups
}

Hamisu M. Salihu, MD, PhD ${ }^{1,2}$, Brisa Y. Garcia, BS ${ }^{1}$, Deepa Dongarwar, MS', Sitratullah O. Maiyegun, MD, MRCP , Korede K. Yusuf, MBBS, MPH, PhD, Dania E. Al Agili, BDS, MPH, DrPH

${ }^{1}$ Center of Excellence in Health Equity, Training, and Research, ${ }^{2}$ Department of Family Medicine, Baylor College of Medicine, Houston, $\mathrm{TX}_{;}{ }^{3}$ Department of Pediatrics, Texas Tech University Health Sciences Center, El Paso, TX; ${ }^{4}$ College of Nursing \& Public Health, Adelphi University, Garden City, NY, USA,

${ }^{5}$ Department of Dental Public Health, Faculty of Dentistry, King Abdulaziz University, Jeddah, Saudi Arabia

\section{Objective}

This study aimed to examine the association between maternal pre-pregnancy underweight and the risk of small-forgestational-age (SGA) birth among Asian Americans compared with non-Hispanic (NH) whites.

\section{Methods}

Using 2014-2018 birth data, we categorized maternal underweight and SGA according to severity. Bivariate analyses were performed to examine the demographics and maternal body mass index (BMI). Adjusted logistic regression models were used to analyze the association between maternal BMI and SGA among Asian Americans compared with NH-Whites.

\section{Results}

In Asian Americans, the likelihood of SGA birth was higher among underweight mothers than among mothers with a normal BMI (odds ratio [OR], 1.37; 95\% confidence interval [Cl], 1.30-1.46). We observed that as the severity of maternal underweight increased, the adjusted odds of SGA increased. Underweight Asian American mothers were more likely to give birth to SGA infants than underweight NH-White mothers (OR, 1.36; 95\% Cl, 1.28-1.44).

\section{Conclusion}

This study shows the association between maternal underweight and SGA birth among Asian Americans, supporting the development of culture-sensitive interventions addressing the impact of weight on pregnancy.

Keywords: Asian Americans; Low birth weight; Small for gestational age; Pregnancy outcomes

\section{Introduction}

Asian Americans represent a fast-growing population in the USA and encompass a heterogeneous population of ethnic subgroups. The six largest Asian American groups are Chinese, Asian Indian, Filipino, Japanese, Korean, and Vietnamese [1]. Compared with non-Hispanic (NH) Whites, Asian Americans have a very low prevalence of pre-pregnancy overweight or obesity, and the prevalence of pre-pregnancy obesity is even lower among immigrant women in each ethnic group than among USA-born women [2]. In contrast, the prevalence of underweight is higher in Asian Americans (5\%) than in NH-Whites (2\%). Among Asian Americans, Vietnam-
Received: 2021.07.21. Revised: 2021.09.07. Accepted: 2021.09.22. Corresponding author: Deepa Dongarwar, MS

Center of Excellence in Health Equity, Training and Research, Baylor College of Medicine, 3701 Kirby Drive, Houston 77098, TX, USA

E-mail: deepa.dongarwar@bcm.edu

https://orcid.org/0000-0002-7338-0636

Articles published in Obstet Gynecol Sci are open-access, distributed under the terms of the Creative Commons Attribution Non-Commercial License (http://creativecommons org/licenses/by-nc/3.0/) which permits unrestricted non-commercial use, distribution, and reproduction in any medium, provided the original work is properly cited.

Copyright $\odot 2021$ Korean Society of Obstetrics and Gynecology 


\section{Obstetrics \& Gynecology Science}

Hamisu M. Salihu, et al. Pre-pregnancy underweight and SGA risk among Asian Americans

ese and Japanese Americans have the highest prevalence of underweight (10.9\%), whereas Filipino Americans have the lowest prevalence of underweight (1.6\%) [3]. Moreover, the prevalence of severe birth outcomes differs between Asian Americans and NH-Whites [4-6]. A retrospective cohort study using data from 1992 to 2018 observed that Asian Americans had lower odds of preterm birth than $\mathrm{NH}$-Whites [4]. It was also previously reported that Asian Americans of advanced maternal age had reduced odds of hypertensive disorders of pregnancy and large-for-gestational-age birth; however, they had increased odds of small-for-gestationalage (SGA) birth compared with NH-Whites [5].

Maternal pre-pregnancy body mass index (BMI) is an important determinant of adverse maternal and infant outcomes [7-11]. In underweight pregnant mothers, an increased risk of fetal loss, preterm birth, anemia, infection, fetal intrauterine growth retardation (IUGR), and SGA birth has been observed [12]. Studies have shown that SGA infants or those with IUGR have higher neonatal mortality and morbidity rates than infants whose weights are appropriate for gestational age (AGA) [7-14]. In addition, SGA infants are more likely to develop neurodevelopmental disabilities in childhood [14] and are at an increased risk of obesity and non-communicable diseases in adulthood [15].

Across all BMI categories, maternal weight gain below the 2009 Institute of Medicine (IOM) recommendation was associated with a higher risk of SGA than maternal weight gain within the recommendation. This association was the greatest in the underweight category of pre-pregnancy BMI [16]. A systematic review of healthy pregnant women from Asia found that most pregnant Indian women attained lower gestational weight than the IOM recommendation compared with other Asian pregnant women, in addition to having a higher risk of low birth weight, SGA, and preterm birth [17]. In another study, maternal weight gain and smoking status were important predictors of delivery of SGA infants in Japanese women in the underweight $\left(\mathrm{BMl}<18 \mathrm{~kg} / \mathrm{m}^{2}\right)$ and $18 \leq \mathrm{BMl} \leq 21 \mathrm{~kg} / \mathrm{m}^{2}$ categories [6]. Similarly, Korean underweight women had a higher adjusted risk of giving birth to IUGR and SGA infants than their normal-weight counterparts. Furthermore, the rates of maternal and neonatal complications were significantly higher among underweight Korean women with inadequate gestational weight gain [18]. However, no study has examined maternal underweight and adverse pregnancy outcomes among Asian American women.

The purpose of this study was to examine the association between pre-pregnancy underweight and SGA risk among the six largest Asian American subgroups using a nationally representative database. This study may aid in better understanding the relationship between maternal weight and SGA birth in Asian Americans, as well as guide the customization and delivery of appropriate prenatal care to optimize prepregnancy maternal weight and prevent adverse neonatal outcomes.

\section{Materials and methods}

\section{Data collection}

This retrospective study was conducted using the 2014-2018 natality data files obtained from the National Vital Statistics System (NVSS) and compiled by the National Center for Health Statistics (NCHS) [19]. Data on sociodemographic and health characteristics as well as maternal risk factors associated with each birth were abstracted from the birth certificates filed in the vital statistics offices of each state in the USA. Because this study was conducted using publicly available, de-identified data, it was classified as exempt by the Internal Review Board of Baylor College of Medicine.

We utilized birth information among Asian American and $\mathrm{NH}-$ White mothers who had singleton births during 20142018, within the gestational ages of 20-41 weeks. Starting in 2014, the NCHS changed the method of measuring gestational age in these data files from that based on the last menstrual period to that based on the obstetric estimate of gestational age. Therefore, we utilized data from 2014 onwards for this study.

\section{Measures}

We categorized infants who were in the $<10$ th percentile of weight for gestational age as SGA, based on a national reference [20]. The SGA births were further subdivided into the following categories: 1) mild SGA, defined as infants in the 5 th to $<10$ th percentile of weight for gestational age, 2) moderate SGA, defined as infants in the 1 st to $<5$ th percentile of weight for gestational age, and 3) severe SGA, defined as infants in the <1st percentile of weight for gestational age. Maternal underweight was classified into the following categories: 1) mild underweight, defined as BMI 


\section{Obstetrics \& Gynecology Science}

Vol. 64, No. 6, 2021

Table 1. Birth characteristics stratified according to maternal body mass index category

\begin{tabular}{|c|c|c|c|c|c|c|}
\hline & $\begin{array}{c}\text { Total } \\
(n=916,449)\end{array}$ & $\begin{array}{c}\text { Normal } \\
(n=909,049)\end{array}$ & $\begin{array}{c}\text { Mild } \\
\text { underweight } \\
(n=6,705)\end{array}$ & $\begin{array}{c}\text { Moderate } \\
\text { underweight } \\
(n=475)\end{array}$ & $\begin{array}{c}\text { Severe } \\
\text { underweight } \\
(n=220)\end{array}$ & $P$-value \\
\hline Size for gestational age & & & & & & $<0.01$ \\
\hline SGA & 14.90 & 14.86 & 18.97 & 24.42 & 23.18 & \\
\hline Non-SGA & 85.10 & 85.14 & 81.03 & 75.58 & 76.82 & \\
\hline Maternal age (yr) & & & & & & $<0.01$ \\
\hline$<19$ & 0.63 & 0.63 & 0.64 & 1.26 & 2.73 & \\
\hline $20-29$ & 30.26 & 30.18 & 39.19 & 46.74 & 53.64 & \\
\hline $30-39$ & 63.53 & 63.60 & 56.20 & 49.68 & 41.36 & \\
\hline $40-49$ & 5.53 & 5.54 & 3.94 & 2.32 & 2.27 & \\
\hline Missing & 0.06 & 0.06 & 0.03 & 0.00 & 0.00 & \\
\hline Birth facility & & & & & & $<0.01$ \\
\hline Hospital & 37.96 & 37.94 & 41.30 & 38.53 & 35.91 & \\
\hline Others & 0.20 & 0.20 & 0.27 & 0.21 & 0.45 & \\
\hline Unknown & 61.84 & 61.87 & 58.43 & 61.26 & 63.64 & \\
\hline Delivery method & & & & & & $<0.01$ \\
\hline Vaginal & 65.03 & 64.95 & 75.21 & 74.32 & 75.91 & \\
\hline C-section & 34.56 & 34.64 & 24.79 & 25.68 & 24.09 & \\
\hline Missing & 0.41 & 0.41 & 0.00 & 0.00 & 0.00 & \\
\hline Birth attendant & & & & & & $<0.01$ \\
\hline Medical professionals & 99.19 & 99.19 & 99.12 & 99.16 & 99.55 & \\
\hline Other & 0.75 & 0.75 & 0.79 & 0.84 & 0.45 & \\
\hline Unknown & 0.06 & 0.06 & 0.09 & 0.00 & 0.00 & \\
\hline Sex & & & & & & $<0.01$ \\
\hline Male & 51.79 & 51.79 & 51.81 & 51.79 & 51.36 & \\
\hline Female & 48.21 & 48.21 & 48.19 & 48.21 & 48.64 & \\
\hline Early prenatal care & & & & & & $<0.01$ \\
\hline No & 16.16 & 16.15 & 16.93 & 17.47 & 22.27 & \\
\hline Yes & 80.34 & 80.33 & 80.70 & 80.00 & 75.91 & \\
\hline Missing & 3.50 & 3.51 & 2.37 & 2.53 & 1.82 & \\
\hline Smoking & & & & & & $<0.01$ \\
\hline No & 98.22 & 98.22 & 98.85 & 98.32 & 98.18 & \\
\hline Yes & 0.45 & 0.45 & 0.36 & 0.63 & 0.91 & \\
\hline Missing & 1.33 & 1.33 & 0.79 & 1.05 & 0.91 & \\
\hline Diabetes & & & & & & $<0.01$ \\
\hline No & 33.92 & 33.88 & 38.99 & 37.89 & 32.73 & \\
\hline Yes & 4.21 & 4.23 & 2.55 & 0.84 & 3.64 & \\
\hline Missing & 61.87 & 61.89 & 58.46 & 61.26 & 63.64 & \\
\hline Chronic hypertension & & & & & & $<0.01$ \\
\hline No & 36.90 & 36.87 & 41.06 & 38.53 & 36.36 & \\
\hline Yes & 1.23 & 1.24 & 0.48 & 0.21 & 0.00 & \\
\hline Missing & 61.87 & 61.89 & 58.46 & 61.26 & 63.64 & \\
\hline
\end{tabular}




\section{Obstetrics \& Gynecology Science}

Hamisu M. Salihu, et al. Pre-pregnancy underweight and SGA risk among Asian Americans

Table 1. Continued

\begin{tabular}{|c|c|c|c|c|c|c|}
\hline & $\begin{array}{c}\text { Total } \\
(n=916,449)\end{array}$ & $\begin{array}{c}\text { Normal } \\
(n=909,049)\end{array}$ & $\begin{array}{c}\text { Mild } \\
\text { underweight } \\
(n=6,705)\end{array}$ & $\begin{array}{c}\text { Moderate } \\
\text { underweight } \\
(n=475)\end{array}$ & $\begin{array}{c}\text { Severe } \\
\text { underweight } \\
(n=220)\end{array}$ & $P$-value \\
\hline Pregnancy hypertension & & & & & & $<0.01$ \\
\hline No & 37.81 & 37.78 & 41.45 & 38.74 & 36.36 & \\
\hline Yes & 0.32 & 0.33 & 0.09 & 0.00 & 0.00 & \\
\hline Missing & 61.87 & 61.89 & 58.46 & 61.26 & 63.64 & \\
\hline Eclampsia & & & & & & $<0.01$ \\
\hline No & 38.07 & 38.04 & 41.54 & 38.74 & 36.36 & \\
\hline Yes & 0.06 & 0.06 & 0.00 & 0.00 & 0.00 & \\
\hline Missing & 61.87 & 61.89 & 58.46 & 61.26 & 63.64 & \\
\hline Any comorbidity & & & & & & $<0.01$ \\
\hline No & 94.59 & 94.57 & 96.94 & 98.95 & 96.36 & \\
\hline Yes & 5.41 & 5.43 & 3.06 & 1.05 & 3.64 & \\
\hline
\end{tabular}

Values are presented as percents.

SGA, small-for-gestational-age.

in the range of $17.00-<18.49,2)$ moderate underweight, defined as BMI in the range of $16.00-<17.00$, and 3) severe underweight, defined as $\mathrm{BMl}<16$ [21].

The covariates considered in this study were maternal age (categorized as <20 years, 20-29 years, 30-39 years, and 40-49 years), birth facility (divided into hospital and others [including freestanding birth centers, clinic/doctor's office, and home]), birth attendants (categorized as medical professionals [including doctors and nurses] and others), plurality (stratified as singletons, twins, and higher-order multiples [triplets or more]), and delivery method (classified as vaginal delivery and cesarean section). We created a composite variable termed "early prenatal care" based on whether prenatal care for the mother was initiated in the 1st trimester. Maternal smoking status and comorbidities (diabetes, chronic/ pregnancy-related hypertension, and eclampsia) were also considered as covariates. A composite variable named "any comorbidity" was created to capture the presence of any of the four aforementioned comorbidities.

\section{Analysis}

We calculated the rates of SGA phenotypes according to the maternal BMI categories. Bivariate analyses between birth characteristics and maternal BMI categories were performed using Pearson's chi-square test. We also calculated the association between maternal BMI (normal versus underweight) and SGA birth among Asian American mothers using a logistic regression model. Furthermore, for Asian American mothers, the association between maternal underweight phenotypes (with normal BMI as the reference) and SGA was evaluated. Lastly, after restricting the data to women who were underweight, logistic regression modeling was employed to compute the adjusted odds of SGA in Asian Americans when compared with $\mathrm{NH}$-Whites within each maternal underweight subcategory. All association models were assessed after excluding missing data from the exposure, outcome, and covariates and were adjusted for age, mode of delivery, smoking status, early prenatal care, and any maternal comorbidity. Data analyses were conducted using $R$ (version 3.5.1) and RStudio (version 1.1.423). All tests of hypotheses were two tailed, with the type- 1 error rate set at $5 \%$. Code availability: The codes will be made available upon request.

\section{Results}

A total of 916,449 mothers were identified as Asian Americans in the dataset, corresponding to $6.26 \%$ of the total births in the USA within the study period. Of the 916,449 mothers analyzed, 136,551 (14.90\%) had SGA births, 909,049 (99\%) had a normal BMI, and 7,400 (0.8\%) were underweight.

Table 1 lists the characteristics of birth according to ma- 


\section{Obstetrics \& Gynecology Science}

Vol. 64, No. 6, 2021

ternal BMI. In the normal weight, mildly underweight, and moderately underweight maternal BMI categories, births were most common in the 30-39 years maternal age group (63.60\%, 56.20\%, and $49.68 \%$, respectively). In the severely underweight maternal BMI category, the most predominant age group was $20-29$ years, accounting for $53.64 \%$. In $>60 \%$ of births, the facility where delivery occurred was not stated. There were more male than female births across all BMI categories. The frequency of cesarean section significantly diminished with increasing degree of maternal underweight, and nearly all births were attended by qualified professionals. The prevalence of maternal smoking was low $(<1 \%)$ and was the highest in the severe underweight category $(0.91 \%)$. The prevalence of comorbidities ranged from $1 \%$ to $5 \%$, and the prevalence of chronic hypertension, pregnancy-related hypertension, and eclampsia showed an inverse dose-response relationship to the underweight status. In contrast, diabetes showed a more complex frequency distribution (U-shaped) across the maternal underweight categories.

Fig. 1 depicts the rates of overall SGA and each SGA phenotype categorized according to maternal BMI status. Across

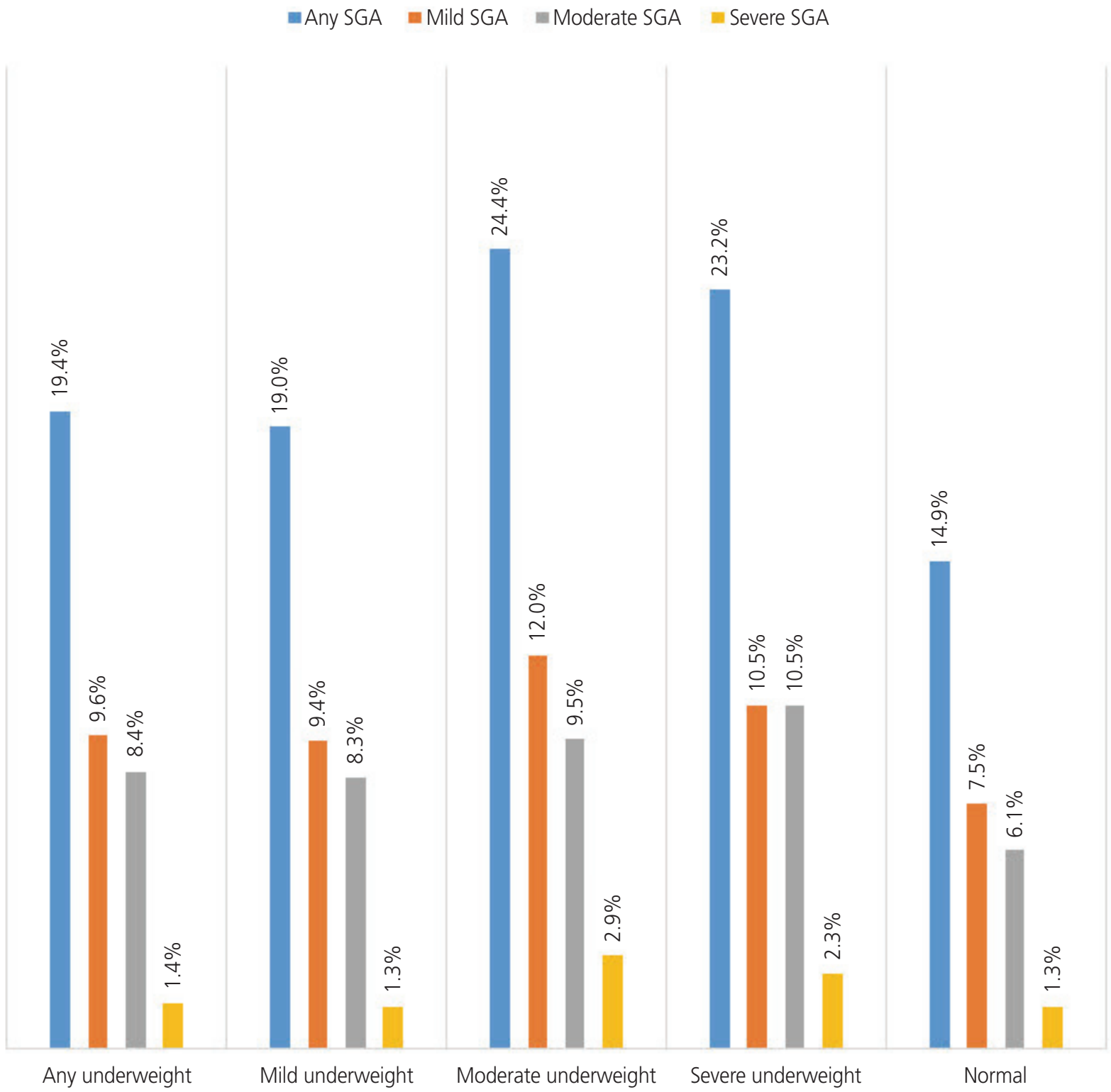

Fig. 1. Rates of small-for-gestational-age (SGA) phenotypes according to maternal body mass index status. 


\section{Obstetrics \& Gynecology Science}

Hamisu M. Salihu, et al. Pre-pregnancy underweight and SGA risk among Asian Americans

all SGA phenotypes, underweight mothers had a greater frequency of SGA birth than mothers with a normal BMI. While the rate of severe SGA birth among mothers in the mild underweight category was similar to that among mothers with a normal BMI (1.3\%), the overall SGA rate and the rates of other SGA phenotypes were greater in mildly underweight mothers. Any $(24.4 \%)$, mild $(12.0 \%)$, and severe $(2.9 \%)$ SGA phenotypes were most frequently observed in mothers classified in the moderate underweight category, whereas the moderate SGA phenotype occurred with the highest frequency in mothers in the severe underweight category (10.5\%).

Table 2 summarizes the results of the logistic regression model that tested the hypothesis of an association between maternal underweight and SGA birth among Asian American women. The results showed that the adjusted odds of SGA were $37 \%$ greater among mothers who were classified as underweight than among those with a normal BMI (odds

Table 2. Adjusted odds ratios for the association of maternal body mass index and other characteristics with small-for-gestational-age birth among Asian American mothers

\begin{tabular}{|c|c|c|}
\hline & OR $(95 \% \mathrm{Cl})$ & $P$-value \\
\hline \multicolumn{3}{|l|}{ BMI } \\
\hline Normal & \multicolumn{2}{|c|}{ Reference } \\
\hline Underweight & $1.37(1.30-1.46)$ & $<0.01$ \\
\hline \multicolumn{3}{|c|}{ Maternal age (yr) } \\
\hline$<19$ & $1.14(1.07-1.22)$ & $<0.01$ \\
\hline $20-29$ & \multicolumn{2}{|c|}{ Reference } \\
\hline $30-39$ & $0.87(0.86-0.88)$ & $<0.01$ \\
\hline $40-49$ & $0.77(0.75-0.79)$ & $<0.01$ \\
\hline \multicolumn{3}{|l|}{ Delivery method } \\
\hline Vaginal & \multicolumn{2}{|c|}{ Reference } \\
\hline C-section & $1.03(1.02-1.05)$ & $<0.01$ \\
\hline \multicolumn{3}{|l|}{ Any comorbidity } \\
\hline No & \multicolumn{2}{|c|}{ Reference } \\
\hline Yes & $1.23(1.20-1.26)$ & $<0.01$ \\
\hline \multicolumn{3}{|l|}{ Smoking } \\
\hline No & \multicolumn{2}{|c|}{ Reference } \\
\hline Yes & $1.16(1.07-1.26)$ & $<0.01$ \\
\hline \multicolumn{3}{|c|}{ Early prenatal care } \\
\hline Yes & \multicolumn{2}{|c|}{ Reference } \\
\hline No & $0.96(0.95-0.98)$ & $<0.01$ \\
\hline
\end{tabular}

$\mathrm{OR}$, odds ratio; $\mathrm{Cl}$, confidence interval; $\mathrm{BMI}$, body mass index. ratio $[\mathrm{OR}], 1.37 ; 95 \%$ confidence interval $[\mathrm{Cl}], 1.30-1.46)$. Younger maternal age, delivery via cesarean section, any comorbidity, and prenatal smoking were associated with a significant increase in SGA frequency regardless of the maternal BMI category. Although early prenatal care was associated with some increase in the likelihood of SGA, the magnitude was modest (4\%).

We further tested the hypothesis that the relationship between maternal underweight and SGA is dose dependent (i.e., with an increase in the severity of maternal underweight, from mild to moderate to severe, the likelihood of SGA would increase). The results of the hypothesis test are presented in Table 3. We observed a progressive increment in the adjusted odds of SGA with increasing severity of maternal underweight among mothers in the moderate and severe underweight categories. The association between the other

Table 3. Association of maternal body mass index and other characteristics with small-for-gestational-age birth among Asian American mothers

\begin{tabular}{|c|c|c|}
\hline & OR $(95 \% \mathrm{Cl})$ & $P$-value \\
\hline \multicolumn{3}{|l|}{ BMl } \\
\hline Normal & \multicolumn{2}{|c|}{ Reference } \\
\hline Mild underweight & $1.33(1.25-1.42)$ & $<0.01$ \\
\hline Moderate underweight & $1.82(1.47-2.24)$ & $<0.01$ \\
\hline Severe underweight & $1.67(1.21-2.27)$ & $<0.01$ \\
\hline \multicolumn{3}{|l|}{ Maternal age (yr) } \\
\hline$<19$ & $1.14(1.07-1.22)$ & $<0.01$ \\
\hline $20-29$ & \multicolumn{2}{|c|}{ Reference } \\
\hline $30-39$ & $0.87(0.86-0.88)$ & $<0.01$ \\
\hline $40-49$ & $0.77(0.75-0.79)$ & $<0.01$ \\
\hline \multicolumn{3}{|l|}{ Delivery method } \\
\hline Vaginal & \multicolumn{2}{|c|}{ Reference } \\
\hline C-Section & $1.03(1.02-1.05)$ & $<0.01$ \\
\hline \multicolumn{3}{|l|}{ Any comorbidity } \\
\hline No & \multicolumn{2}{|c|}{ Reference } \\
\hline Yes & $1.23(1.20-1.26)$ & $<0.01$ \\
\hline \multicolumn{3}{|l|}{ Smoking } \\
\hline No & \multicolumn{2}{|c|}{ Reference } \\
\hline Yes & $1.16(1.07-1.26)$ & $<0.01$ \\
\hline \multicolumn{3}{|l|}{ Early prenatal care } \\
\hline Yes & \multicolumn{2}{|c|}{ Reference } \\
\hline No & $0.96(0.95-0.98)$ & $<0.01$ \\
\hline
\end{tabular}




\section{Obstetrics \& Gynecology Science}

Vol. 64, No. 6, 2021

variables and SGA remained the same as in Table 2.

In Fig. 2, we tested the hypothesis that the occurrence of SGA would be greater among Asian Americans than among their White counterparts and that the disparity would widen with the severity of underweight. The findings showed that Asian American mothers who were classified as underweight had a 36\% greater adjusted odds of delivering an SGA infant than $\mathrm{NH}$-White mothers $(\mathrm{OR}, 1.36 ; 95 \% \mathrm{Cl}, 1.28-1.44)$. This racial disparity was also evident among mothers in the mild and moderate groups, but not among those in the severe underweight category.

\section{Discussion}

In this large population-based study, we found that Asian American mothers with pre-pregnancy underweight (prepregnancy $\mathrm{BMI}<18.5 \mathrm{~kg} / \mathrm{m}^{2}$ ) had higher odds of giving birth to SGA infants than their Asian American counterparts with a normal BMI (pre-pregnancy BMI between 18.5 and
$24.9 \mathrm{~kg} / \mathrm{m}^{2}$ ). A dose-response relationship was also observed, in which an increase in the severity of maternal underweight resulted in an increase in the adjusted odds of SGA among mothers in the moderate and severe underweight categories. We also found that Asian American mothers who were classified as underweight had higher adjusted odds of delivering an SGA infant than underweight NH-White mothers. This racial disparity persisted in mothers with mild and moderate levels of underweight, but not in those with severe underweight.

Pre-pregnancy BMI is a well-studied determinant of birth outcomes. However, little is known about this relationship in the Asian American population. Only a few studies have examined the association between suboptimal maternal prepregnancy BMI and SGA risk in Asian populations, and those studies have yielded inconsistent results [22-28]. In the current study, we observed a higher risk of SGA birth among underweight Asian American mothers than among normalweight Asian American mothers, which contradicts the findings from previous studies [22,23]. Akahoshi et al. [22], in a

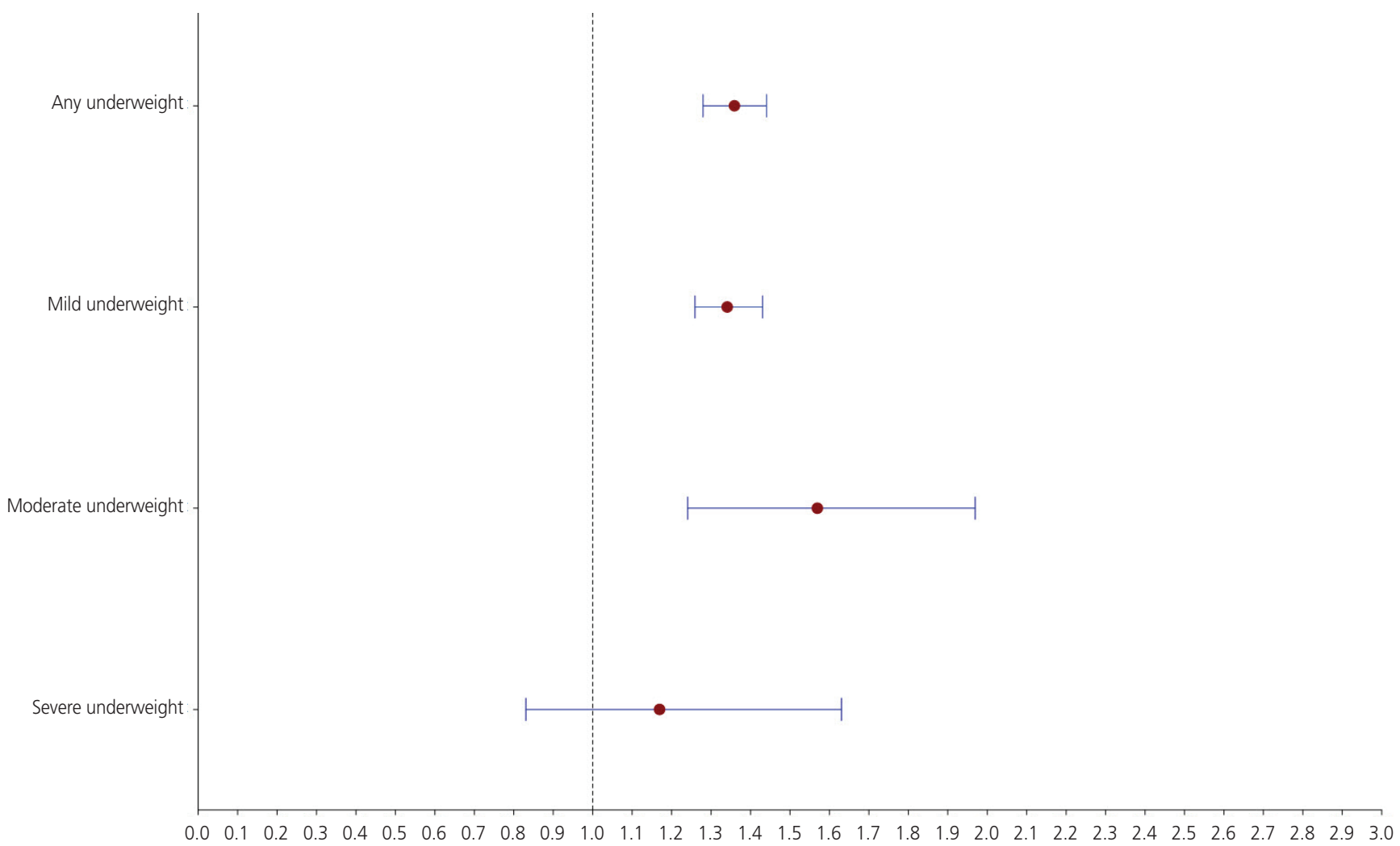

Fig. 2. Risk of small-for-gestational-age in Asian Americans compared with non-Hispanic-Whites within each maternal underweight subcategory. 


\section{Obstetrics \& Gynecology Science}

Hamisu M. Salihu, et al. Pre-pregnancy underweight and SGA risk among Asian Americans

study conducted among Japanese women, found an insignificant statistical association between maternal underweight and SGA birth (adjusted OR, 1.91; $95 \% \mathrm{Cl}, 0.96-3.83$ ). Only 49 underweight women were included in their study, and this lack of power might have accounted for the lack of association despite the observed increased risk. In a Chinese population, Xiao et al. [23] found no relationship between pre-pregnancy underweight in mothers and SGA in preterm infants. The lack of consistency with our findings may be related to differences in the study inclusion criteria and potential confounding factors that were considered. However, the positive association between maternal pre-pregnancy underweight and SGA risk in the current study was consistent with the finding of most previous studies in Asian women in Asian countries [24-28]. In a 2016 population-based cohort study conducted in Wuhan, China, Zhang et al. [24] reported that pre-pregnancy underweight $\left(\mathrm{BMl}<18.5 \mathrm{~kg} / \mathrm{m}^{2}\right)$ was associated with a $40 \%$ increased risk of SGA. In 2012, Liu et al. [28] also observed that maternal pre-pregnancy underweight was a risk factor for SGA in their prospective study of approximately 300,000 births in China. This may be due to inadequate nutrient intake leading to diminished fetal growth [25]. Our findings may also be explained by other associated risk factors that were not controlled for in this study, including socioeconomic status and medical illnesses.

We observed that as the severity of maternal underweight increased, the severity of SGA worsened. This dose-dependent pattern may support a causal relationship between maternal underweight and SGA risk. We also found that younger maternal age, any comorbidity, and prenatal smoking, irrespective of maternal underweight status, were all associated with a higher SGA risk. Medical conditions [29], smoking [22], and maternal age are well-known risk factors for SGA birth.

In the current study, Asian American mothers who were classified as underweight had higher adjusted odds of delivering an SGA infant than their underweight NH-White counterparts. A racial disparity in the risk of SGA birth has been previously reported [5]. Although the etiology related to this disparity is unclear, inadequate weight gain during pregnancy and low socioeconomic status may be contributing factors. A previous study suggested that Asian women have a higher risk of inadequate gestational weight gain (GWG) than White women [30], which could be a potential pathway leading to SGA, as adequate gestational weight gain sup- ports fetal growth and development. Additional studies are needed to fully elucidate the underlying etiology associated with this disparity.

This study had some limitations. First, pre-pregnancy weight was self-reported and thus may be inaccurate. A recent study that compared preconception weight measured from electronic health records and recalled pre-pregnancy weight found a high correlation between the two measures, with higher risks of misclassification in overweight and obese women than in normal-weight women [25]. Accordingly, the probability of misclassification of pre-pregnancy weight in our study is expected to be low. Second, owing to a lack of data on some potential confounders, we were unable to control for important influencing factors, including socioeconomic status, alcohol consumption, and poor diet/low caloric intake. Previous studies have found that the risk of adverse outcomes could differ among Asian American subgroups. In this study, we did not perform stratified analysis according to Asian American subgroups, as related data are not available in the database that we used. Moreover, our study only included women who were identified as Asian Americans or NH-Whites. We did not include women with more than one race, as the findings of such an analysis would be difficult to interpret. Furthermore, although iron or nutritional supplementation has been observed to improve fetal growth [31], we were unable to consider nutritional supplementation in our study because this information was not available in the dataset. Despite these limitations, our study had several strengths. To our knowledge, this is the first populationbased study in the USA that examined the relationship between maternal underweight and SGA risk in Asian Americans. This retrospective birth cohort study utilized the most recent data from the NVSS natality dataset and had a large sample size $(n=916,449)$.

Our study demonstrated an association between maternal pre-pregnancy underweight and SGA birth in the Asian American population. Moreover, our findings showed that, overall, underweight Asian American women had a higher likelihood of giving birth to SGA infants than their underweight NH-White counterparts. Previous studies have not examined the association between maternal underweight and SGA birth among Asian Americans. Our study also strengthens the notion that underweight women should be counseled on the risk of adverse birth outcomes and the importance of attaining optimal pre-pregnancy BMI when 


\section{Obstetrics \& Gynecology Science}

Vol. 64, No. 6, 2021

planning a pregnancy. Further studies are required to determine causal pathways as well as to develop appropriate and culture-sensitive interventions that can mitigate the impact of suboptimal gestational weight gain among underweight pregnant women, especially Asian Americans, who have a high prevalence of underweight.

\section{Conflict of interest}

All authors report no conflicts of interest.

\section{Ethical approval}

This study does not require approval of the Institutional Review Board because no patient data is contained in this article. The study was performed in accordance with the principles of the Declaration of Helsinki.

\section{Patient consent}

Written informed consent and the use of images from patients are not required for the publication.

\section{Funding information}

This study was classified as exempt by the Internal Review Board of Baylor College of Medicine. Research funding was provided by the USA Department of Health and Human Services and Health Resources and Services Administration for Baylor College of Medicine Center of Excellence in Health Equity, Training, and Research (grant no. D34HP31024).

\section{References}

1. Lauderdale DS, Rathouz PJ. Body mass index in a US national sample of Asian Americans: effects of nativity, years since immigration and socioeconomic status. Int J Obes Relat Metab Disord 2000;24:1188-94.

2. Singh GK, DiBari JN. Marked disparities in pre-pregnancy obesity and overweight prevalence among US
Women by race/ethnicity, nativity/immigrant status, and sociodemographic characteristics, 2012-2014. J Obes 2019;2019:2419263.

3. Barnes PM, Adams PF, Powell-Griner E. Health characteristics of the Asian adult population: United States, 20042006. Adv Data 2008;(394):1-22.

4. Dongarwar D, Tahseen D, Wang L, Aliyu MH, Salihu HM. Trends and predictors of preterm birth among Asian Americans by ethnicity, 1992-2018. J Matern Fetal Neonatal Med 2021 Mar 11 [Epub]. https://doi.org/10.1080/ 14767058.2021.1900103.

5. Dongarwar D, Tahseen D, Aliyu MH, Salihu HM. Pregnancy outcomes among Asian Americans of advanced maternal age, 1992-2018. J Obstet Gynaecol Res 2021;47:2117-25.

6. Lee KJ, Sohn S, Hong K, Kim J, Kim R, Lee S, et al. Maternal, infant, and perinatal mortality statistics and trends in Korea between 2009 and 2017. Obstet Gynecol Sci 2020;63:623-30.

7. Watanabe $H$, Inoue $K$, Doi M, Matsumoto M, Ogasawara K, Fukuoka $\mathrm{H}$, et al. Risk factors for term small for gestational age infants in women with low prepregnancy body mass index. J Obstet Gynaecol Res 2010;36:506-12.

8. Liu L, Ma Y, Wang N, Lin W, Liu Y, Wen D. Maternal body mass index and risk of neonatal adverse outcomes in China: a systematic review and meta-analysis. BMC Pregnancy Childbirth 2019;19:105.

9. Neggers Y, Goldenberg RL. Some thoughts on body mass index, micronutrient intakes and pregnancy outcome. J Nutr 2003;133(5 Suppl 2):1737S-40.

10. Liu P, Xu L, Wang Y, Zhang Y, Du Y, Sun Y, et al. Association between perinatal outcomes and maternal prepregnancy body mass index. Obes Rev 2016;17:1091102.

11. Kim HY, Lee D, Kim J, Noh E, Ahn KH, Hong SC, et al. Secular trends in cesarean sections and risk factors in South Korea (2006-2015). Obstet Gynecol Sci 2020;63:440-7.

12. Triunfo S, Lanzone A. Impact of maternal under nutrition on obstetric outcomes. J Endocrinol Invest 2015;38:318.

13. Sekiya N, Anai T, Matsubara M, Miyazaki F. Maternal weight gain rate in the second trimester are associated with birth weight and length of gestation. Gynecol Ob- 


\section{Obstetrics \& Gynecology Science}

Hamisu M. Salihu, et al. Pre-pregnancy underweight and SGA risk among Asian Americans

stet Invest 2007;63:45-8.

14. Ehrenberg HM, Dierker L, Milluzzi C, Mercer BM. Low maternal weight, failure to thrive in pregnancy, and adverse pregnancy outcomes. Am J Obstet Gynecol 2003;189:1726-30.

15. McMillen IC, Adam CL, Mühlhäusler BS. Early origins of obesity: programming the appetite regulatory system. J Physiol 2005;565(Pt 1):9-17.

16. Goldstein RF, Abell SK, Ranasinha S, Misso M, Boyle JA, Black $\mathrm{MH}$, et al. Association of gestational weight gain with maternal and infant outcomes: a systematic review and meta-analysis. JAMA 2017;317:2207-25.

17. Arora P, Tamber Aeri B. Gestational weight gain among healthy pregnant women from Asia in comparison with Institute of Medicine (IOM) guidelines-2009: a systematic review. J Pregnancy 2019;2019:3849596.

18. Choi SK, Park IY, Shin JC. The effects of pre-pregnancy body mass index and gestational weight gain on perinatal outcomes in Korean women: a retrospective cohort study. Reprod Biol Endocrinol 2011;9:6.

19. Centers for Disease Control and Prevention. The National Vital Statistics System-birth data [Internet]. Atlanta (GA): Centers for Disease Control and Prevention; c2021 [cited 2021 Apr 23]. Available from: https://www.cdc. gov/nchs/nvss/births.htm.

20. Alexander GR, Himes JH, Kaufman RB, Mor J, Kogan M. A United States national reference for fetal growth. Obstet Gynecol 1996;87:163-8.

21. Skills You Need Ltd. BMI- Body Mass Index [Internet]. Lampeter (UK): Skills You Need Ltd; c2021 [cited 2021 Apr 23]. Available from: https://www.skillsyouneed.com/ ps/bmi.html.

22. Akahoshi E, Arima K, Miura K, Nishimura T, Abe Y, Yamamoto $N$, et al. Association of maternal pre-pregnancy weight, weight gain during pregnancy, and smoking with small-for-gestational-age infants in Japan. Early Hum Dev 2016;92:33-6.
23. Xiao L, Ding G, Vinturache A, Xu J, Ding Y, Guo J, et al. Associations of maternal pre-pregnancy body mass index and gestational weight gain with birth outcomes in Shanghai, China. Sci Rep 2017;7:41073.

24. Zhang B, Yang S, Yang R, Wang J, Liang S, Hu R, et al. Maternal prepregnancy body mass index and small for gestational age births in Chinese women. Paediatr Perinat Epidemiol 2016;30:550-4.

25. Han Z, Mulla S, Beyene J, Liao G, McDonald SD; Knowledge Synthesis Group. Maternal underweight and the risk of preterm birth and low birth weight: a systematic review and meta-analyses. Int J Epidemiol 2011;40:65101.

26. Chen YH, Li L, Chen W, Liu ZB, Ma L, Gao XX, et al. Prepregnancy underweight and obesity are positively associated with small-for-gestational-age infants in a Chinese population. Sci Rep 2019;9:15544.

27. Li N, Liu E, Guo J, Pan L, Li B, Wang P, et al. Maternal prepregnancy body mass index and gestational weight gain on pregnancy outcomes. PLoS One 2013;8:e82310.

28. Liu Y, Dai W, Dai X, Li Z. Prepregnancy body mass index and gestational weight gain with the outcome of pregnancy: a 13-year study of 292,568 cases in China. Arch Gynecol Obstet 2012;286:905-11.

29. Ota E, Ganchimeg T, Morisaki N, Vogel JP, Pileggi C, Ortiz-Panozo $E$, et al. Risk factors and adverse perinatal outcomes among term and preterm infants born smallfor-gestational-age: secondary analyses of the WHO multi-country survey on maternal and newborn health. PLoS One 2014;9:e105155.

30. Guo Y, Miao Q, Huang T, Fell DB, Harvey AL, Wen SW, et al. Racial/ethnic variations in gestational weight gain: a population-based study in Ontario. Can J Public Health 2019;110:657-67.

31. Lowensohn Rl, Stadler DD, Naze C. Current concepts of maternal nutrition. Obstet Gynecol Surv 2016;71:41326. 